\title{
The Correlation Between Serum Ferritin and Liver Function in Children with Thalassemia Mayor
}

\author{
Muhamad Akbar*, Selvi Nafianti, Rizky Ardiansyah \\ Email: akbar pai@yahoo.co.id \\ Pediatric Department, Faculty of Medicine USU, Medan, Indonesia \\ Pediatric Department, Faculty of Medicine USU \\ Dr. Mansyur No.5 Padang Bulan Street, Medan Baru, Medan, Indonesia
}

\begin{abstract}
Background: Iron overload in thalassemia major patients required regular blood transfusions due to ineffective erythropoiesis. Iron overload is a common chronic complication caused by increased iron absorption. Iron in the body will bind to ferritin. As the main iron storage in the body is in the liver, the iron overload will cause liver damage that reflects in high Serum Glutamic Oxaloacetic Transaminase (SGOT) and Serum Glutamic Pyruvic Transaminase (SGPT) level. This study will describe the relationship between serum ferritin and Serum SGOT and SGPT level so that it can be used as a marker of high iron levels in the body.

Methods: This was an observational analytic study with a cross-sectional design which carried out in the Hemato-Oncology Division of H. Adam Malik Hospital Medan November - December 2019. A total of 30 thalassemia major patients who were fulfilled the inclusions criteria were taken by consecutive sampling and were tested for serum ferritin, SGOT, and SGPT level.

Results: Of the 30 samples, $43.3 \%$ of the subjects were male and $46.7 \%$ of the children suffering from malnutrition. The median number of transfusions was 93 times $(40-202)$, the mean serum ferritin level was $1422 \mathrm{mcg} / \mathrm{L}$ (285 - 3441), the mean SGOT level was $35 \mathrm{U} / \mathrm{L}$ (11 - 167), and the mean SGPT level was $28 \mathrm{U}$ / L (6 - 268). The relationship between the number of transfusions and ferritin levels, SGOT and SGPT level were $\mathrm{r} 0.102 ; p$ : $0.592, \mathrm{r} 0.162 ; p: 0.932, \mathrm{r} 0.134 ; p 0.481$. In addition, the relationship between serum ferritin levels and SGOT and SGPT were r 0.285; $p 0.127$, r 0.274; $p 0.142$, respectively.
\end{abstract}

Conclusion: There was no relationship between serum ferritin and liver function in thalassemia major.

Keywords: thalassemia major, ferritin serum, SGOT, SGPT

\section{Background}

About 100,000 thalassemia patients are currently living by routine transfusion, and at least 3,000 die each year in their teens or early 20s from uncontrolled iron overload (Modell B and Darlison M, 2008). Data from the Indonesian Thalassemia Foundation and the Association of Parents of Indonesian Thalassemia Patients (YTI / POPTI) in 2012, there were 4,896 cases of thalassemia major and in 2017 continued to increase to 8,616 cases (Indonesian Thalassemia Foundation, 2019)

A transfusion is a therapeutic option for beta-thalassemia major patients, this therapy is given for life so that it has complications that can endanger the sufferer, namely iron accumulation. This excess iron will cause cirrhosis and hepatocellular carcinoma (Wahidayat PA, 2019) Cirrhosis and hepatocellular carcinoma is one of the complications of iron accumulation, cirrhosis begins with liver fibrosis which is not reversible. The prevalence of cirrhosis is reported to be 10-40\%. (Aldouri M A et al., 1087)] The prevalence of liver fibrosis 
is reported to be $30-40 \%$. (Wulandari R D, 2018) Damage to hepatocytes begins to accumulate within a year of initiating a transfusion or after 0-20 transfusions. (Li C et al., 2002)

The liver stores one-third of the body's iron in hepatocytes which constitute $80 \%$ of the total liver mass that binds to ferritin. (Indonesian Thalassemia Foundation, 2019) Excess iron that does not bind to ferritin will damage hepatocytes and cause cell death. The dead cells will be phagocytes by Kupffer cells and activate Stellate cells so that collagen formation occurs which is a sign of liver cirrhosis. (Wahidayat PA 2019; Ogilvie C and Fitzsimons E, 2012)

Ferritin is an intracellular protein that stores iron where the main synthesis location is in hepatocytes. (Milic S., et al 2012; 9Garcia P, et al., 2017) Hepatocytes have two pathways to take iron from the circulation, namely by transferrin which is bound to iron under normal conditions, and through non-transferrin bound iron (NTBI). in iron overload. [Kohgo Y, et al., 2008; Origa R, 2017) The occurrence of hepatocellular injury can impair cell membrane permeability and lead to leakage of the enzyme aspartate aminotransferase (AST) or serum glutamic oxaloacetic transaminase (SGOT) and alanine aminotransaminase (ALT) or serum glutamic pyruvic transaminase (SGPT) into the extracellular compartment. (Wahidiyat P, et al 2018; ] 13Trehan A, et al., 2015)

Liver injury is a condition that describes the onset of symptoms before liver damage occurs. Serum glutamic oxaloacetic transaminase (SGOT) and serum glutamic pyruvic transaminase (SGPT) are specific liver biochemicals to assess the occurrence of liver damage, before other markers of liver damage increase. (Ogilvie C and Fitzsimons E, 2012; Garcia P, et al., 2017) Early detection of liver damage through liver biochemistry will prevent the occurrence of liver damage permanent. Therefore, biochemical examination and evaluation of the liver can be used as early detection of liver injury in children with thalassemia major (Origa R, 2017;14Moiz B, et al., 2018) The purpose of this study was to analyze the relationship between liver biochemistry and serum ferritin in thalassemia major patients at RSUP Haji Adam Malik Medan.

\section{Methods}

This research is a cross-sectional study conducted on patients with thalassemia major who were treated in the pediatric hemato-oncology division of the H Adam Malik General Hospital, Medan, November 2019 December 2019. The sample size was calculated based on the sample size formula to test hypotheses in the population using a correlation analysis design. . The calculation was carried out using a $95 \%$ confidence level with a sample size of at least 11 patients. All subjects will be asked for parental consent after an explanation of the disease condition is made. Inclusion criteria were patients with thalassemia major who had received iron chelation for at least 1 year and had received iron chelation. Exclusion criteria were patients with other chronic diseases and the use of hepatotoxic drugs. The study was carried out under the provisions of the Health Ethics Committee of the Faculty of Medicine, University of North Sumatra (No: 931 / KEP / USURSUPHAM / 2019).

History taking, physical examination, and recording patient data are done through medical records and when the patient arrives. Laboratory tests are performed when the patient comes for treatment. Blood tests including SGOT, SGPT, Ferritin. All data obtained were recorded and analysed

\section{Statistical analysis}

Univariate analysis was performed for demographic and clinical data to obtain the distribution of sample characteristics. Numeric data will be displayed as mean and standard deviation. Categorical data will be displayed in terms of frequency and percentage. Bivariate analysis was used to determine the correlation between liver biochemistry and serum ferritin levels. The Pearson correlation test will be used if the data is normally distributed, while the Spearman correlation test will be used if the data is not normally distributed. Data processing was performed using the Statistical Package for Social Sciences for Windows (SPSS) computerized system version 22 with a $95 \%$ confidence interval (CI) and a significance level of $\mathrm{P}<0.05$. 


\section{Results}

This research was conducted on 30 children with thalassemia major. Baseline characteristics data shows that the percentage of women is $56 \%$ more than that of men $43 \%$, ranging in age from 3 years to 16 years, with a mean number of transfusions of 93 times. a median serum ferritin level of $1422 \mathrm{mcg} / \mathrm{L}$ and median SGOT 35, and median SGPT $28 \mathrm{U} / \mathrm{L}$. The data on the characteristics of the research sample can be seen in Table 1

This study assessed the relationship between the number of transfusions and the value of ferritin, SGOT, and SGPT in thalassemia major children as shown in Table 4.2, the results showed that there was no significant relationship between the number of transfusions and ferritin $r=0.102, p=0.592$ the number of transfusions with SGPT $r=0.160 \mathrm{p}=0.932$ and the number of transfused with SGOT $\mathrm{r}=0.134 . \mathrm{P}=0.481$ This study also looked at the relationship between ferritin and SGOT and SGPT where the results showed that there was no relationship between ferritin and SGOT $r=0.285, \mathrm{p}=0.127$ and ferritin with SGPT $\mathrm{r}=0.274, \mathrm{p}$ $=0.142$ as shown in table 2

\section{Discussion}

Thalassemia is a hereditary blood disorder and is inherited in an autosomal recessive manner and is not linked to sex chromosomes. (Trehan A, 2015) The pattern of inheritance of this type of disease has a $25 \%$ chance of being affected by homozygous defects and 50\% in heterozygous defects. (Trehan A, 2015) 40 In our study, 13 $(43.3 \%)$ were boys and $17(56.7 \%)$ were boys. female genitalia suffering from thalassemia major. This result is different from several previous studies which found that there were more men than women with thalassemia (Moiz B, et al 2018;15HammodH, et al., 2018)

In our study, the mean age of children with thalassemia major was 7.4 years. This is different from studies that have been reported. A study in India reported the demographic characteristics of 964 children with thalassemia major who had not been transfused and found the mean age of the children was 13.2 months (Trehan A, et al, 2010). This is not following our study because the mean age of children in the study was 88.5 months. Lack of parental awareness of the child's condition causes the diagnosis of patients with thalassemia when the child has severe anemia, this condition causes the patient to be diagnosed with thalassemia major too late. In thalassemia major, age under 2 years is the age at which severe anemia symptoms are found (Galanello R and OrigaR., 2010)

The results of our study found that as many as 14 people (46.7\%) with thalassemia major were malnourished, 7 people $(23 \%)$ were malnourished, 8 people $(26.7 \%)$ were well nourished, and 1 person $(3.3 \%)$ was obese. This is following the previous research conducted in Bahawalpur with a total of 305 research subjects. The study found that $58.6 \%$ of the subjects were malnourished, $35.7 \%$ with good nutrition, $3.2 \%$ with overnutrition, and $2.3 \%$ with obesity (Sheikh M A, 2017) Growth disturbances in thalassemia patients are caused by various factors, including hormonal factors due to hemochromatosis in the endocrine glands and tissue hypoxia due to anemia (Arijanty L and Nasar S S., 2016). Other factors that play a role in the growth of thalassemia patients are genetic and environmental factors where nutrition is an important environmental factor in influencing the development of children. Severe anemia and a large spleen cause decreased appetite, so that food intake is reduced, resulting in nutritional disorders (Arijanty L and Nasar S S., 2016)

Besides, in thalassemia, there is a hemolysis process resulting in chronic anemia which results in tissue hypoxia. Chronic hypoxia causes impaired nutrient use at the cellular level, resulting in impaired growth. (Biswas B 2020) Optimal nutrition is essential for thalassemia as a modality in long-term treatment and for preventing nutritional disorders, growth disorders, late puberty development, and immune deficiencies that may be associated with secondary malnutrition (Soliman A T, et al 2004)

The transfusion is a treatment for thalassemia major, each blood bag contains an iron component. One unit of treated donor blood from $420 \mathrm{~mL}$ contains about $200 \mathrm{mg}$ of iron, or about $0.47 \mathrm{mg} / \mathrm{mL}$ of donor blood. Each year about 100-200 ml/kg body weight of packed red cell (PRC) are transfused. This equates to an annual intake of $116-232 \mathrm{mg}$ of iron/ $\mathrm{kg}$ body weight, or 0.32-0.64 mg/kg/day (PorterJ B and GarbowskiM., 2014) 
Transfusion therapy aims to maintain normal growth and suppress the ineffectiveness of erythropoiesis. Excess iron cannot be avoided in thalassemia sufferers, especially in those who do not use chelation properly (Ardalan FA, et al., 2004) The majority of iron circulating in the body binds to ferritin, this is what bases ferritin usually as a marker of excess iron in the body(Milic S, 2016). In this study, the median of transfusions was 93 times since diagnosed with thalassemia major. The results of a study in India showed that after receiving a transfusion of 30 bags, the ferritin value increased to over $1000 \mathrm{ng} / \mathrm{ml}$ (Galanello $\mathrm{R}$ and Origa R., 2010) In our study, no correlation was found between the number of transfusions obtained and an increase in serum ferritin $\mathrm{p}=0.592(\mathrm{r}=0.102)$. In another study, the survival rate of children with thalassemia majority received routine transfusions and adequate iron chelation therapy for 10 years was $99 \%$ but decreased after 20 years of age (Porter J B and Garbowski M., 2014)

The liver is the largest organ as an iron deposit in the body compared to other organs, so that excess iron will directly impact the organs that function as reserves for iron deposits, the liver is also an organ that regulates iron regulation through hepcidin and ferroportin, the liver regulates the uptake and excretion of iron in the body (Garcia, P. C. R, et al., 2007) In our study, it was found that there was no significant relationship between the amount of ferritin and the levels of SGOT $(p=0.127 \mathrm{r}=0.285)$ and SGPT $(\mathrm{p}=0.147 \mathrm{r}=0.274)$. This could be due to the iron chelation given to this patient. A longitudinal study in pediatric patients with thalassemia major showed improvement in liver function after optimal iron chelation (Deferasirox) administration of $20 \mathrm{mg} / \mathrm{kgbb} /$ day [24]. Several studies have also reported that a cut-off value of ferritin> 2500 mcq / L correlates with elevated liver enzymes (Ogilvie C and Fitzsimons., 2012; Kaddah A, et all., 2005) A study evaluating AST and ALT values after iron chelation administration in thalassemia major patients, found no increase in AST and ALT (Wahidayat PA 2019) This is consistent with the results of our research. Another study in India showed a strong association between increased ferritin and increased AST and ALT in thalassemia major patients who received chelation iron $r=0.84$ ( $p<0.001$ ) (Rameshwar L, et al., 2016)

Besides, elevated liver enzymes in children with thalassemia major who receive routine transfusions are associated with the incidence of hepatitis $\mathrm{C}$ infection (Ehsan H, et al., 2020) In this study, there was limited information from medical records so we did not report the results of routine screening for markers of hepatitis virus infection (Ameli M, et al., 2008). In our study, there was no significant relationship between transfusion frequency and AST levels $(r=0.16)$ and SGPT $(0.134)$ in thalassemia major children who received iron chelation. Further research is still needed in developing detection of liver injury in children with thalassemia major.

Table 1. Research Basic Characteristic

\begin{tabular}{ll}
\hline Variable & $\mathbf{n = 3 0 ( \% )}$ \\
\hline $\begin{array}{l}\text { Gender } \\
\text { Male (n, \%) }\end{array}$ & $13(43.3)$ \\
$\quad$ Female (n, \%) & $17(56.7)$ \\
& \\
Nutritional Status & $7(23)$ \\
$\quad$ Malnutrition (n, \%) & $14(46.7)$ \\
$\quad$ Underweight (n, \%) & $8(26.7)$ \\
$\quad$ Normal (n, \%) & $1(3.3)$ \\
$\quad$ Overweight (n, \%) & $7.4(3-16.3)$ \\
Age (years), median (range) & $93(40-202)$ \\
Transfusions count & \\
\hline
\end{tabular}


Ferritin (mcq/L), median (range) $1422(285-3441)$

SGOT (U/L), median (range)

$35(11-167)$

SGPT (U/L), median (range)

$28(6-268)$

Table 2. Transfusion count correlation with ferritin levels, SGOT and SGPT

\begin{tabular}{clc}
\hline & \multicolumn{2}{c}{ Transfusion Count } \\
\cline { 2 - 3 } & $\mathbf{r}$ & $p$ \\
\hline Feritin (mcq/L) & 0,102 & 0.592 \\
SGPT (U/L) & 0.160 & 0.932 \\
SGOT (U/L) & 0.134 & 0.481 \\
\hline
\end{tabular}

* Spearman Correlation

Table 3. Correlation of feritin levels with SGOT and SGPT

\begin{tabular}{lccc} 
& Median (range) & r & $p$ \\
\hline Feritin levels (mcq/L) & $1422.5(285-3441)$ & 0.285 & 0.127 \\
SGOT (U/L) & $35.0(11-167)$ & & \\
& & & \\
Feritin levels (mcq/L) & $1422.5(285-3441)$ & 0.274 & 0.142 \\
SGPT (U/L) & $28(6-268)$ & & \\
\hline
\end{tabular}

(10 pt) Here introduce the paper, and put a nomenclature if necessary, in a box with the same font size as the rest of the paper. The paragraphs continue from here and are only separated by headings, subheadings, images and formulae. The section headings are arranged by numbers, bold and 10 pt. Here follows further instructions for authors.

\section{References}

Aldouri, M. A., Wonke, B., Hoffbrand, A. V., Flynn, D. M., Laulicht, M., Fenton, L. A., ... \& Brown, D., 1987. Iron state and hepatic disease in patients with thalassaemia major, treated with long term subcutaneous desferrioxamine. Journal of clinical pathology, 40(11), p.1353-1359.

Ameli, M., Besharati, S., Nemati, K., \& Zamani, F., 2008. Relationship between elevated liver enzyme with iron overload and viral hepatitis in thalassemia major patients in Northern Iran. Saudi medical journal, 29(11), p. 1611-1615. 
Ardalan, F. A., Osquei, M. R., Toosi, M. N., \& Irvanloo, G., 2004. Synergic effect of chronic hepatitis $\mathrm{C}$ infection and beta thalassemia major with marked hepatic iron overload on liver fibrosis: a retrospective cross-sectional study. BMC gastroenterology, 4(1), p.17.

Arijanty, L., \& Nasar, S. S., 2016. Masalah nutrisi pada thalassemia. Sari Pediatri, 5(1), p. 21-6.

Biswas, B., Naskar, N. N., Basu, K., Dasgupta, A., Basu, R., \& Paul, B., 2020. Malnutrition, Its Attributes, and Impact on Quality of Life: An Epidemiological Study among $\beta$-Thalassemia Major Children. Journal of the Korean Academy of Family Medicine.

Ehsan, H., Wahab, A., Anwer, F., Iftikhar, R., \& Yousaf, M. N., 2020. Prevalence of Transfusion Transmissible Infections in Beta-Thalassemia Major Patients in Pakistan: A Systematic Review. Cureus, 12(8).

Garcia, P. C. R., Longhi, F., Branco, R. G., Piva, J. P., Lacks, D., \& Tasker, R. C., 2007. Ferritinlevels in children with severe sepsis and septic shock. Acta paediatrica, 96(12), p.1829-1831

Galanello, R., \& Origa, R., 2010. Beta-thalassemia. Orphanet journal of rare diseases, 5(1), p. 11.

Hammod, H. A. N. A. N. J. A. S. S. I. M., Mokif, T. A., \& Al-harbi, H. J., 2018. The correlation between thalassemia with body mass index and blood groups in children and adult patient in the province of babylon, Iraq. Asian Journal of Pharmaceutical and Clinical Research, 11(9), p. 509-12.

Indonesian Thalassemia Foundation. Thalassemia [Internet]. [Cited on 20th May 2019]. Available from: https://www.thalassaemia-yti.org/

Kohgo, Y., Ikuta, K., Ohtake, T., Torimoto, Y., \& Kato, J. 2008. Body iron metabolism and pathophysiology of iron overload. International journal of hematology, 88(1), p. 7-15.

Kaddah, A., El-Shabrawi, M., Saleh, A., Al Gaithy, A., \& Basalama, A., 2005. Liver iron content and histological findings versus serum ferritin in detection of different grades of hemosiderosis in hepatic diseases in thalassemia major. JAC, 6, p. 475-84.

Li, C. K., Chik, K. W., Lam, C. W. K., To, K. F., Yu, S. C. H., Lee, V., ... \& Yuen, P. M. P.,2002.Liver disease in transfusion dependent thalassaemia major. Archives of disease in childhood, 86(5), p.344-347.

Milic, S., Mikolasevic, I., Orlic, L., Devcic, E., Starcevic-Cizmarevic, N., Stimac, D., ... \& Ristic, S.,2016. The role of iron and iron overload in chronic liver disease. Medical science monitor: international medical journal of experimental and clinical research, 22, p.2144.

Modell, B., \& Darlison, M.,2008. Global epidemiology of haemoglobin disorders and derived service indicators. Bulletin of the World Health Organization, 86, p.480-487. 
Moiz, B., Habib, A., Sawani, S., Raheem, A., Hasan, B., \& Gangwani, M., 2018. Anthropometric measurements in children having transfusion-dependent beta thalassemia. Hematology, 23(4), p. 248-252..

Origa, R., 2017. $\beta$-Thalassemia. Genetics in Medicine, 19(6), p. 609-619.

Ogilvie, C., \& Fitzsimons, E., 2012. Serum Ferritin and Iron Studies-Laboratory Reporting and Clinical Application in Primary Care. INTECH Open Access Publisher.

Porter, J. B., \& Garbowski, M., 2014. The pathophysiology of transfusional iron overload. Hematology/oncology clinics, 28(4), p. 683-701.

Rameshwar, L., Suman, A. S., Meena, P., \& Goyal, S., 2016. Correlation of liver enzymes with serum ferritin levels in $\beta$-thalassemia major. Int J Res Med Sci, 4(8), p. 32713274.

Sheikh, M. A., Shakir, M. U., \& Shah, M. U. H. A. M. M. A. D., 2017. The assessment of nutritional status of children with beta thalassemia major with body mass index. Pak $\mathrm{J}$ Med Health Sci, 11, p. 262-5.

Soliman, A., Yassin, M., Al Yafei, F., Al-Naimi, L., Almarri, N., Sabt, A., \& De Sanctis, V., 2014. Longitudinal study on liver functions in patients with thalassemia major before and after deferasirox (DFX) therapy. Mediterranean Journal of Hematology and Infectious Diseases, 6(1).

Soliman, A. T., El-Matary, W., Fattah, M. M. A., Nasr, I. S., El Alaily, R. K., \& Thabet, M. A., 2004. The effect of high-calorie diet on nutritional parameters of children with $\beta$ thalassaemia major. Clinical Nutrition, 23(5), p. 1153-1158.

Trehan, A., Sharma, N., Das, R., Bansal, D., \& Marwaha, R. K., 2015. Clinicoinvestigational and demographic profile of children with thalassemia major. Indian Journal of Hematology and Blood Transfusion, 31(1), p. 121-126.

Wahidayat PA. Get to know thalassemia [Internet]. [Cited on 20th May 2019]. Available from: http://www.idai.or.id/artikel/seputar-keseh-anak/mengenal-thalassemia.

Wahidiyat, P. A., Iskandar, S. D., Rahmartani, L. D., \& Sekarsari, D. 2018. Liver iron overload and hepatic function in children with thalassemia major. Paediatricalndonesiana, 58(5), p. 233-7.

Wulandari, R. D., 2018. Kelainan pada Sintesis Hemoglobin: Thalassemia dan Epidemiologi Thalassemia. Jurnal IImiah Kedokteran Wijaya Kusuma, 5(2), p. 33-44. 